\title{
O JOGO COMO UM RECURSO PEDAGÓGICO PARA INICIAÇÃO ESPORTIVA NO ENSINO FUNDAMENTAL II
}

\author{
Anderson Aparecido da Silva, José Ricardo Silva \\ Faculdade de Presidente Prudente - FAPEPE. Departamento de Educação Física, Presidente Prudente - SP. E-mail: \\ andersonaps@live.com
}

\section{RESUMO}

As aulas de Educação Física em âmbito escolar têm sido marcadas, historicamente, por práticas esportivistas excludentes. De modo geral, o esporte quando empregado nas escolas apresenta características de treinamento, alto rendimento. Com estas características exclui as crianças menos habilidosas e cria desinteresses por esta prática cultural. Por isso, o objetivo deste texto é apresentar o jogo como recurso pedagógico para o ensino dos esportes nas séries iniciais do ensino fundamental II. Para realização desta pesquisa usamos o método de pesquisa bibliográfica. De acordo com os autores aqui estudados o jogo, por possuir caráter lúdico, envolve a criança para a prática da atividade, sem fazer com que perca o interesse por conta da cobrança de desempenho físico e movimentos padronizados. Acredita-se que o professor ao utilizar os jogos pré-desportivos para esta finalidade, os alunos terão contato com elementos dos esportes tais como, fundamentos, regras, táticas, etc. de forma mais atrativa e menos excludente.

Palavras-chave: Educação Física; Escola; Esporte; Cultura Corporal; Jogo.

\section{PLAY AS A TEACHING FOR SPORTS INITIATION IN BASIC EDUCATION II}

\begin{abstract}
The physical education classes in school settings have been marked historically by esportivistas exclusionary practices. In general, the sport when employed in schools presentms characteristics of training high performance. With these features excludes the less smkilled children and creates disinterest by this cultural practice. Therefore, the aim of this mpaper is to present the game as a teaching resource for the teaching of sports in the emmarly grades of elementary school. For this research we used the method of literature research. According to the authors here studied the game, have playful nature, involves the child to practice the activity, without making it lose interest due to the recovery of mphysical performance and standardized movements. We believe the teacher to use the games for this purpose, students will have contact with elements such as sports, fundamentals, rules, tactics, etc. more attractive and less exclusionary way.

Keywords: Physical Education; School; Sport; Body culture; Game.
\end{abstract}

\section{INTRODUÇÃO}

A Educação Física possui uma trajetória histórica com grandes nuances possíveis de serem observadas ainda hoje nas práticas docentes. Tais atuações se justificam, além das nuances históricas, pela desvalorização do professor, do baixo investimento em materiais e/ou estrutura, pela falta do processo de formação continuada e em serviço, enfim, obstáculos que prejudicam o 
desenvolvimento e a função enquanto componente curricular escolar frente às demais disciplinas e à sociedade de forma geral.

Devido a estas problemáticas as práticas pedagógicas, por vezes, apresentavam-se predominantemente esportivistas, com características de treinamento. Neste modelo de aula, alunos que não apresentavam habilidades esportivas, eram excluídos pelos outros alunos ou até mesmo pelo próprio professor.

Neste sentido, o jogo surge como ferramenta pedagógica que pode auxiliar nas práticas pedagógicas que objetivam a mediação do esporte enquanto conteúdo da cultura corporal já que traz como uma de suas características a ludicidade. Essa perspectiva vai contra ao modelo mecanicista de Educação Física escolar que se apresenta como um modelo de aula que não possibilita a inovação do próprio aluno de conhecer outras possibilidades do esporte. Nesta visão o professor ensina as regras, as técnicas, as táticas dos esportes e, ao aluno, basta reproduzi-las com perfeição ${ }^{1}$.

Assim, o objetivo desta pesquisa é apresentar o jogo como um recurso pedagógico indicado ao ensino dos esportes nas escolas, acreditando que seja uma ferramenta importante ao ser trabalhada visando um ensino inclusivo e para despertar o interesse e a vontade nos alunos de levarem está prática cultural também para fora do âmbito escolar.

\section{METODOLOGIA}

Para o desenvolvimento de nossa pesquisa, foi utilizada a pesquisa bibliográfica. Esta metodologia de pesquisa caracteriza-se como aquela que auxilia o pesquisador no resgate de conhecimentos acumulados para o aprofundamento teórico da temática em questão ${ }^{2}$.

\section{RESULTADOS}

Diante do objetivo nesta pesquisa, é de extrema relevância apresentar as tendências que constituíram e fizeram parte da Educação Física, que, sem dúvida tiveram um papel importante para o desenvolvimento da profissão. É necessário destacar a forma e a visão de trabalho de cada abordagem predominante em cada época.

Assim sendo, serão apresentadas tendências que nortearam a Educação Física, que, por um determinado tempo, foram marcadas pelo regimento do militarismo, que segundo Guimarães ${ }^{3}$ visavam com a educação física à ordem e o progresso, pois era de fundamental importância à formação de indivíduos fortes e saudáveis para a defesa da pátria e seus ideais. 
Na Educação Física higienista o foco era a higiene, o pudor, o aspecto moral e intelectual e a dimensão física, onde cabia a Educação Física favorecer a educação do corpo, tendo como meta a constituição de um físico saudável e equilibrado organicamente, menos suscetível às doenças ${ }^{4}$.

Posteriormente, surge a educação física competitivista. Esta visava desenvolver o esporte e desenvolver técnicas de eficiência, buscando aprimorar o físico e a técnica do individuo. No ano 1930 a educação física passou a ser usada de forma a melhorar o desempenho do trabalhador nas indústrias, trabalhando a cooperação e o grupo visando uma melhora na produção. No ano de 1950-1960, a educação física do Brasil visa integrar a rede pública como uma disciplina educativa por excelência, estribando-se na tendência pedagogicista que visa formar o cidadão ${ }^{3}$.

No ano de 1964 a educação física é influenciada pelo movimento tecnicista. Segundo os Parâmetros Curriculares Nacionais (PCN's) a Educação Física teve seu caráter instrumental reforçado pelo caráter prático voltado para o desempenho técnico e físico do aluno ${ }^{4}$.

Decorrente de todo este processo de aprendizagem e da busca pela melhoria do homem e seu desempenho, tanto no âmbito social, como no cognitivo e afetivo, o homem se viu sempre em busca de desenvolver recursos de ensino aprendizagem que atendesse o objetivo proposto e necessário para cada época.

Em 1970-1980 a educação física é presenteada pelo surgimento da psicomotricidade, contribuindo muito para o desenvolvimento, tanto no âmbito social como no escolar, centrandose no desenvolvimento das condutas motoras ${ }^{5}$.

A partir do ano de 1990 a educação física é alicerçada na cultura corporal. Nesta abordagem, é trabalhada com o aluno a importância dos movimentos construídos historicamente, visto que o indivíduo não é um atleta tecnicamente perfeito ou um aglomerado de músculos a ser esculpido, mas é, antes de tudo, um sujeito social, que vive e se movimenta historicamente. Essa nova visão sobre a Educação Física passa a considerar como dimensões essenciais para a compreensão do novo conceito, o aspecto afetivo, político, social e cultural.

Devemos lembrar a importância que teve o papel da Educação Física dentro do âmbito escolar neste processo, onde o ato pedagógico nos leva a adquirir conhecimentos do desenvolvimento da cultura corporal resgatando a historia, na qual os movimentos corporais foram evoluindo, modificando, e assim, construindo uma cultura, onde não somente se desenvolveu o corpo, mas também o cognitivo e o social ${ }^{5}$. 
Historicamente, as abordagens ${ }^{1}$ também desenvolveram papel importante neste processo. Dentre elas, podemos destacar: a desenvolvimentista, a construtivista, a saúde renovada, a crítico superadora e a crítico emancipatória.

$\mathrm{Na}$ abordagem desenvolvimentista o foco principal é o desenvolvimento maturacional e o movimento, sendo que o desenvolvimento cultural e social é deixado em segundo plano 4 .

A abordagem construtivista considera o conhecimento que o aluno já possui, ou seja, valorizando e resgatando a cultura, onde a aquisição do conhecimento faz parte do processo construído durante toda a sua vida, não passivamente, de acordo com as pressões do meio ${ }^{4}$.

Já a abordagem saúde renovada considera que a Educação Física não pode consistir apenas em modalidades esportivas e jogos, e sim, valorizar a prática de exercícios para a promoção da saúde, onde o objetivo é informar, mudar atitudes e hábitos ${ }^{6}$.

A proposta crítico superadora busca trabalhar com o aluno em toda sua complexidade, valorizando e interagindo em grupo, onde trata como objeto de estudo da Educação Física a Cultura Corporal, a partir de conteúdos como jogos, esporte, ginástica, lutas e danças ${ }^{8}$.

Por fim, na abordagem crítico emancipátoria, o desenvolvimento do indivíduo se dá por si só, ou seja, valoriza a compreensão critica do mundo com uma visão individual, onde segundo Hermida, Mata \& Nascimento ${ }^{8}$ a abordagem crítico-emancipátoria compreende a expressividade corporal como forma de linguagem pela qual o homem se relaciona com o meio em que vive, tornando-o sujeito a partir do conhecimento elaborado sobre o outro e sobre si mesmo.

Percebe-se então que as abordagens foram historicamente criadas com o intuito de superar/propor uma nova maneira de trabalhar a Educação Física dentro do mundo escolar, em busca de melhoras no processo de ensino-aprendizagem do homem. No entanto, é comum observarmos, ainda hoje, práticas pedagógicas alicerçadas em abordagens mecanicistas mediante as influências históricas destacadas acima. Contudo, entendemos que cabe aos professores reconhecer nas abordagens pedagógicas aquele projeto de homem e de sociedade que vai ao encontro de seus interesses. Desta forma, queremos destacar, não uma abordagem pedagógica, mas uma ferramenta pedagógica que supere modelos de aulas pautadas em repetição de movimentos estereotipados característicos do alto rendimento, o jogo.

\section{DISCUSSÃO}

O jogo é um recurso pedagógico de ensino que vai contra o modelo tecnicista, mecanicista que por sua vez adotam métodos de ensino que buscam o desenvolvimento e aprimoramento de 
técnicas, trabalhando em cima do modelo analítico-sintético. Para Mendes, Matos e Pinho esse modelo de aula surgiu, inicialmente, nos esportes individuais onde, as habilidades são treinadas anteriormente ao esporte propriamente dito para que, depois, possam ser realizadas no jogo ${ }^{9}$.

Como se no ensino do basquetebol, elegêssemos os movimentos mais comuns, mais frequentes de uma partida, os fundamentos básicos e ensinássemos os alunos cada um dos fundamentos básicos separadamente, fora do contexto de jogo, visando automatização dos movimentos na equivocada esperança de que bastasse aos alunos conhecer "pedaços" em separado para poder praticar ${ }^{4}$.

Mediante a essa visão, o esporte trabalhado de forma repetitiva perde seu caráter de desenvolvimento e aprendizado, pois se transforma em uma prática de ensino maçante para os alunos, despertando o desinteresse pela atividade, valoriza os mais habilidosos e, consequentemente, exclui alunos com pouca desenvoltura para determinados movimentos técnicos. Esta visão de esporte nas aulas de Educação Física escolar contradiz nosso objetivo, onde o interesse é despertar a vontade e o desejo da prática esportiva.

A visão de jogo a qual viemos propor vai contra a esses princípios adotados pelos modelos mecanicista e tecnicista. Propomos o jogo de uma forma lúdica para alcançar objetivos educacionais, o qual é incentivar os alunos a participarem das aulas de Educação Física na escola. Existem diferentes conceituações sobre o termo 'jogo', variáveis temporais que convergem em alguns consensos, dentre eles, a característica lúdica do jogo que favorece a participação dos alunos $^{10}$.

Ao empregarem o jogo, os professores poderão perceber as repercussões no comportamento das crianças, pois ficam mais motivadas, cooperativas, comunicativas, desenvolvem autonomia, confiança em si mesmas, se mostram mais curiosas e dispostas para outras aprendizagens ${ }^{10}$.

O jogo proporciona em meio atípico a aula, um ambiente instável, totalmente propício e facilitador para o aprendizado ${ }^{11}$. Portanto, segundo Leonardo, Scaglia e Reverdito ${ }^{11}$, o professor tem a possibilidade de organizar práticas pautadas nesta perspectiva do jogo e assim, tornar a atividade planejada como será jogada pelos alunos e não apenas executada como atividade qualquer, atingindo seu objetivo de ensino/aprendizagem.

Por isso, valorizar a presença dos jogos nas aulas de educação física, torna-se fundamental para o aprendizado dos esportes em âmbito escolar de forma mais dinâmica já que traz a ludicidade como uma de suas características, envolve todos os alunos do começo ao fim da aula. 
Ao utilizar o jogo como uma ferramenta pedagógica, os problemas relacionados com a exclusão e o desinteresse pelas práticas esportivas não serão sanados por completo, para Lima ${ }^{10}$ esta pretensão é descabida. Contudo, queremos enfatizar que ao propor o jogo como recurso pedagógico no ensino dos esportes os professores estarão viabilizando a participação de todos os alunos e minimizando possibilidades de exclusão. Defendemos que o jogo deva ser trabalhado com alunos visando o desenvolvimento em sua totalidade, onde o aluno aprenda a respeitar os colegas, aprenda a cooperar, a trabalhar em equipe dentro e fora da escola e possa adotar a prática do esporte beneficiando sua saúde e vida em sociedade.

\section{CONSIDERAÇÕES FINAIS}

Historicamente, a educação física tem contribuído para que grande número de alunos não se identifique com as práticas esportivas, devido a experiências práticas vexatórias onde Ihes foram "cobradas" movimentos e desempenho estereotipados pautados em atletas profissionais.

Ao longo do trabalho procuramos defender a utilização de jogos para a iniciação esportiva na educação física escolar. De acordo com os autores utilizados, o jogo por possuir caráter lúdico, envolve os alunos nas aulas práticas possibilitando que conheçam e vivenciem o esporte de forma mais prazerosa e divertida. Esta prática pedagógica contrapõe às aulas de repetição de movimento em busca da técnica perfeita, características típicas do alto rendimento, possibilitando assim, maior envolvimento e participação dos alunos nas atividades, levando-os a conhecer e reconhecer os esportes como manifestações culturais e como práticas corporais saudáveis para seu desenvolvimento e lazer.

\section{REFERÊNCIAS}

1. Junior L, Barbosa F. Um olhar sobre o esporte nas aulas de Educação Física escolar: qual o modelo adotado pelo professor? Revista digital Buenos Aires, Ano15, nำ152, Enero de 2011, 0101.

2. Moresi, Eduardo. Metodologia da pesquisa. Brasília, 2013.

3. Guimarães A, Pellini F, Araujo J, Mazzini. Educação Física Escolar: Atitudes e Valores. Motriz, Vol. 7, n. 1, Jan-Jun, 2001, 17-22.

4. Brasil. Ministério da Educação. Secretaria da Educação Básica. Parâmetros curriculares nacionais, Educação Física: MEC, SEF, 1997.

5. Mello A, Martinez A. As principais tendências pedagógicas da Educação Física e sua relação com a inclusão. Conexões: revista da Faculdade de Educação Física da Unicamp, Campinas, v. 10, n. 2, maio/ago, 2012, 180-195. 
6. Zancha D, Magalhães G, Martins J, Silva A. T, Abrahão B. T. Conhecimento dos professores de Educação Física escolar sobre a abordagem saúde renovada e a temática saúde.

Conexões;revista da faculdade de Educação Física da Unicamp, Campinas, v, 11, n, 1, , jan/mar. 2013, 204-217.

7. Darido S, Rangel I. Educação Física na escola: Implicações para a prática pedagógica. Rio de janeiro; Guanabara Koogan, 2008.

8. Herminida J, Mata A, Nascimento M. A Educação Física crítico-superadora no contexto das pedagogias criticas no Brasil. Anais do v colóquio de Epistemologia da Educação Física. Maceió-Al, Brasil, 22 e 23 de outubro de 2010.

9. Mendes R. Matos J. Pinho A. Propostas Metodológicas da Iniciação Esportiva Escolar. Revista Eletrônica Multidisciplinar Pindorama do Instituto Federal de Educação, Ciência e Tecnologia da Bahia - IFBANo 01 - Ano I - Agosto/2010, 01-01.

10. Lima J. M. O jogo como recurso pedagógico no contexto educacional. São Paulo, Cultura Acadêmica, Universidade Estadual Paulista, Pró-Reitoria de Graduação, 2008.

11. Leonardo L, Scaglia A. Reverdito R. O ensino dos esportes coletivos: Metodologia pautada na família do jogo. Motriz, Rio Claro, v. 15, n. 02, Abr/jun. 2009, 236-246. 